the kidney turned out a large quantity of blood-clot and some urine escaped. A portion of the kidney as large as a walnut, together with some smaller fragments, were found torn off from the rest and were removed. A careful examination of the remainder showed that though contused it was not hopelessly damaged and the ureter appeared to be intact; it was accordingly left. The wound was thoroughly irrigated and a large drainage-tube was inserted and lightly packed around with iodoform gauze. The wound was dressed two or three times a day and at first was urine-soaked; incontinence of the resical urine had been present from the first and persisted, but the amount passed rarely exceeded two pints in the day. On Nov. 11th the urine collected from the wound was acid, that from the bladder being alkaline, and there was some cystitis; the general condition was rapidly improving. At first some seven ounces of urine were collected daily from the wound ; this diminished progressively and by Dec. 4th urine had ceased to come from the wound and on the 11th the wound was healed. The patient was discharged on Jan. 1st, 1901 ; on the three days previously she had passed 63,58 , and 53 ounces of urine.

\section{NORTH WIMBLEDON COTTAGE HOSPITAL.}

\section{A CASE OF TETANIS SUCCESSFULLY TREATED WITH ANTITOXIN.}

(Under the care of Dr. J. E. BATES.)

THE intra-cerebral injection of tetanus antitoxin cannot be said to have passed the experimental stage, and there is no indication of the spread of this method of administering anti-tetanic serum. Certainly some of the cases in which it has been employed are very striking, ${ }^{1}$ but the increased risk is commonly felt not to be compensated by any increased efficiency. Into the question of the value of the serum itself we need hardly enter, it is recognised that when administered early and freely benefit results, but that in many cases its employment does not prevent a fatal result We appreciate the importance of Dr. Bates's case recorded below, but we must not too hastily attribute the favourable issue to the serum or its mode of administration.

A youth, aged 16 years, first came under the care of Dr. J. E. Bates in the North Wimbledon Cottage Hospital on June 11th, 1901, for a compound Colles's fracture of the right arm. The fracture had occurred on the afternoon of that day, about one hour before Dr. Bates saw him. He was a lad occupied on some buildings which were being erected on the site of an old nursery garden. He met with the accident through falling off a scaffold, and when seen the lower end of the ulna had pierced and was protruding through the skin, shirt, and coat-sleeve, both the end of the bone and the coat-sleeve being covered with mud. A temporary dressing, consisting of a very dirty piece of rag, had been placed over the broken end of the bone. After a very careful cleansing: of the wound, a nail-brush being used and an anxsthetic being given, the fracture was reduced after some difficulty and put up in splints. Three days later (on the 14th) there arose much swelling, cedema, and general redness of the forearm and hand with an evening rise of temperature to $102^{\circ} \mathrm{F}$. All these symptoms soon subsided under hot boric fomentations although the wound still continued to discharge freely.

Eleven days after the injury (on June 22nd) the patient noticed that the muscles of his jaw were a little stiff; but the stiffiness was so slight that he omitted to mention it to Dr. Bates when he saw him on that day. The next day (the 23rd) the symptoms had materially increased. He could only get his mouth half open, and this caused him pain. Both sterno-mastoid muscles were tense and he also had difficulty and pain when trying to swallow fluids. On the 24th there was an alarming increase of all the symptoms. The jaw was closed tightly, swallowing of fluids caused choking and dyspnoea and was very painful, the muscles connecting the head and trunk anteriorly and posteriorly were all absolutely rigid, and he complained of painful jerky spasms in his right arm. Dr. Bates saw him in consultation with Mr. E. Pocklington and Mr. R. T. P. Oollyns of Wimbledon, and it was decided to give him the benefit of antitoxin without delay.

On June 24th, at 5 P.M., assisted by Mr. Pocklington and Mr. Collyns, Dr. Bates trephined the patient over the right parietal bone anteriorly and injected five cubic centimetres of antitoxin (obtained from the Jenner Institute of Preventive Medicine) into the right lateral ventricle of the brain, and at the same time 35 cubic centimetres of the antitoxin were injected into the loins. The patient stood the operation well and a marked quickening of the pulse was noticed during the intra-cerebral injection. During the night after the operation the pulse-rate rose to 116 ; but it had dropped to 98 on the next moming and never rose above 100 subsequently. The temperature once after the operation rose to $99^{\circ} 6^{\circ}$, but never higher. For 48 hours after the operation the symptoms showed no signs of amelioration, but, on the other hand, they became no worse. On the 27th (three days after the operation) improvement set in in all the symptoms and was steadily maintained so that by July 6th (12 days after the operation) the patient was allowed to eat-solid food and to sit up out of bed. On July 1st (seven days after the operation) the wound in the head was dressed for the first time and found to be completely healed by first intention.

Bemarks by Dr. BATES. - The points of interest in this case I think are these: (1) the dates of the exciting cause and onset are quite clear and distinct ; (2) the patient at the time of the accident was living an outdoor life and was in robust health; (3) the patient all through the illness never failed to take his nourishment well, although part of the time he had great difficulty and pain in doing so; and (4) the rapid onset of the symptoms, their speedy and alarming progress, the manner in which the injection checked their progress and also the patient's comparatively swift and entire recovery. Finally, I must tender my sincere thanks to $\mathrm{Mr}$. Pocklington and Mr. Collyns, without whose advice and assistance I feel sure the patient would not have made such a rapid and complete recovery from such an awful disease

\section{attedital Socrefires.}

\section{PATHOLOGICAL SOCIETY OF LONDON.}

A Case of Phlegmonous Gastritis due to Streptococous Infection. - A Case of Pneumococcus Gastritis with General Infection. - The Bacteriology of a Case of Rapidlyspreading Gangrene.-The Transmission of Hamolysins from Parents to Offspring.

A MEETING of this society was held on Jan. 21st, Mr. W. WATson Cheyne, the President, being in the chair.

Dr. W. CAYLEY related a case of Phlegmonous Gastritis due to Streptococcus Infection. The patient, a woman, aged 26 years, was admitted into the Middlesex Hospital on Nov. 19th and died on Nov. 21st. She had been taken ill without any assignable cause on Nov. 13th with rigors, sorethroat, headache, and pain in the abdomen and limbs. On the 17th she began to vomit and continued to do so on the 18th; the vomiting was accompanied by severe abdominal pain. On admission she presented all the symptoms of acute general peritonitis with dilatation of the stomach. Her temperature was $104 \cdot 6^{\circ} \mathrm{F}$. She gradually sank and died on the 21st. She had no vomiting or action of the bowels after her admission. At the necropsy there was general suppurative peritonitis; the stomach was dilated and its coats were thickened. On section there was purulent infiltration of all the coats of the stomach between the mucous membrane, which appeared intact, and the peritoneum; this change was most marked over the pyloric third of the organ. Bacteriological examination of the purulent exudation from the submucous coat. showed a number of bacilli which did not stain by Gram's method and which resembled morphologically bacillus coli communis; there were also present a few short chains of streptococci which stained by Gram's method. The other organs presented nothing abnormal. It was probable that the streptococcus infection was primary and the bacillus coli a secondary effect. Dr. Cayley referred to the cases of phlegmonous gastritis collected by Dr. R. F. C. Leith in Vol. IV. of the Edinburgh Hospital Reports and to some which had been published since. Two conditions were necessary, the presence of virulent organisms and a condition of the mucous membrane which would allow them 